\title{
Measuring Pro-Poor Growth
}

Martin Ravallion

Shaohua Chen

New tools allow one to study the incidence of economic growth by initial level of income, and to measure the rate of pro-poor growth in an economy. An application is provided using data for China in the 1990s.

The World Bank

Development Research Group

Poverty

August 2001 


\section{Summary findings}

It is important to know how aggregate economic growth or contraction was distributed according to initial levels of living. In particular, to what extent can it be said that growth was "pro-poor?" There are problems with past methods of addressing this question, notably that the measures used are inconsistent with the properties that are considered desirable for a measure of the level of poverty.

Ravallion and Chen provide some new tools for assessing to what extent the aggregate growth process in an economy is pro-poor. The key measurement tool is the "growth incidence curve," which gives growth rates by quantiles (such as percentiles) ranked by income. Taking the area under this curve up to the headcount index of poverty gives a measure of the rate of pro-poor growth consistent with the Watts index for the level of poverty.

The authors give examples using survey data for China during the 1990s. Over 1990-99, the ordinary growth rate of household income per capita in China was 7 percent a year. The growth rate by quantile varied from 3 percent for the poorest percentile to 11 percent for the richest, while the rate of pro-poor growth was around 4 percent. The pattern was reversed for a few years in the mid-1990s, when the rate of pro-poor growth rose to 10 percent a year-above the ordinary growth rate of 8 percent.

This paper-a product of Poverty, Development Research Group-is part of a larger effort in the group to improve the analytic tools used for monitoring poverty over time and studying the impacts of economywide changes. Copies of the paper are available free from the World Bank, $1818 \mathrm{H}$ Street NW, Washington, DC 20433. Please contact Catalina Cunanan, room MC3-542, telephone 202-473 2301, fax 202-522-1151, email address ccunanan@worldbank.org. Policy Research Working Papers are also posted on the Web at http://econ.worldbank.org. The authors may be contacted at mravallion@worldbank.org or schen@worldbank.org. August 2001. (11 pages)

The Policy Research Working Paper Series disseminates the findings of work in progress to encourage the exchange of ideas about development issues. An objective of the series is to get the findings out quickly, even if the presentations are less than fully polished. The papers carry the names of the authors and should be cited accordingly. The findings, interpretations, and conclusions expressed in this paper are entirely those of the authors. They do not necessarily represent the view of the World Bank, its Executive Directors, or the countries they represent. 


\title{
Measuring pro-poor growth
}

\author{
Martin Ravallion and Shaohua Chen ${ }^{1}$ \\ Development Research Group, World Bank
}

Key words: Economic growth, poverty measurement, China

JEL: D31, I32, O40

1 These are the views of the authors and should not be attributed to the World Bank or any affiliated organization. For their comments we are grateful to Aart Kraay and Tony Shorrocks. The data used here was were kindly provided by the Rural and Urban Household Survey Teams of China's National Bureau of Statistics. The support of a Dutch Trust Fund is gratefully acknowledged. Address for correspondence: mravallion@worldbank.org and schen@worldbank.org. 



\section{Introduction}

A number of countries have been successful in maintaining a high growth rate in average incomes in the 1990s. Other countries have seen aggregate contraction. The question often arises as to how this growth or contraction was distributed according to initial levels of living. In particular, to what extent can it be said that growth has been "pro-poor"?

To assess whether the observed changes in the distribution of income were poverty reducing, one can calculate the distributional component of a poverty measure, as obtained by fixing the mean relative to the poverty line and then seeing how the poverty measure changes (Datt and Ravallion, 1992). This tells us if the actual rate of poverty reduction is higher than one would have expected without any change in the Lorenz curve. ${ }^{2}$ However, it is possible that while the distributional changes were "pro-poor," there was no absolute gain to the poor. Equally well, "pro-rich" distributional shifts may have come with absolute gains to the poor.

A more direct approach is to look at growth rates for the poor. It is common to compare mean incomes across the distribution ranked by income; this is sometimes called "Pen's parade" (following Pen, 1971). To assess whether growth is pro-poor, a natural step from Pen's parade is to calculate the growth rate in the mean of the poorest quintile (say). ${ }^{3}$ Taking this a step further, we define a "growth incidence curve", showing how the growth rate for a given quantile varies across quantiles ranked by income. The following section defines this curve and discusses its properties. Starting from the Watts (1968) index of the level of poverty, we derive in section 3 a

2 For example, Chen and Ravallion (2001) find that the rate of poverty reduction in the developing world as a whole over 1987-98 would have been slightly lower if not for the changes in the aggregate Lorenz curve. The slight improvement in overall distribution from the point of view of the poor was almost solely due to economic growth in China.

3 For example, Dollar and Kraay (2001) test whether aggregate growth is "good for the poor" by calculating the growth rate in the mean of the poorest quintile. 
measure of the rate of pro-poor growth by integration on the growth incidence curve. The measure can be interpreted as the mean growth rate for the poor (as distinct from the growth rate in the mean for the poor). Section 4 illustrates these ideas using data for China in the 1990s.

\section{The growth incidence curve}

Let $F_{t}(y)$ denote the cumulative distribution function (CDF) of income, giving the proportion of the population with income less than $y$ at date $t$. Inverting the CDF at the $p$ 'th quantile gives the income of that quantile:

$$
y_{t}(p)=F_{t}^{-1}(p)=L_{t}^{\prime}(p) \mu_{t} \quad\left(y_{t}^{\prime}(p)>0\right)
$$

(following Gastwirth, 1971), where $L_{t}(p)$ is the Lorenz curve (with slope $L_{t}^{\prime}(p)$ ) and $\mu_{t}$ is the mean; for example, $y_{t}(0.5)$ is the median. Letting $p$ vary from zero to one yields a version of Pen's parade that is sometimes called the "quantile function" (see, for example, Moyes, 1999).

Comparing two dates, $t-1$ and $t$, the growth rate in income of the $p$ 'th quantile is $g_{t}(p)=\left[y_{t}(p) / y_{t-1}(p)\right]-1$. Letting $p$ vary from zero to one, $g_{l}(p)$ traces out what we will call the "growth incidence curve" (GIC). It follows from (1) that:

$$
g_{t}(p)=\frac{L_{t}^{\prime}(p)}{L_{t-1}^{\prime}(p)}\left(\gamma_{t}+1\right)-1
$$

where $\gamma_{t}=\left(\mu_{t} / \mu_{t-1}\right)-1$ is the growth rate in $\mu_{t}$. It is evident from (2) that if the Lorenz curve does not change then $g_{t}(p)=\gamma_{t}$ for all $p$. Also $g_{t}(p)>\gamma_{t}$ if and only if $y_{t}(p) / \mu_{t}$ is increasing over time. If $g_{t}(p)$ is a decreasing (increasing) function for all $p$ then inequality falls (rises) 
over time for all inequality measures satisfying the Pigou-Dalton transfer principle. ${ }^{4}$ If the GIC lies above zero everywhere $\left(g_{t}(p)>0\right.$ for all $\left.p\right)$ then there is first-order dominance (FOD) of the distribution at date $t$ over $t$-1. If the GIC switches sign then one cannot in general infer whether higher-order dominance holds by looking at the GIC alone. ${ }^{5}$

\section{Measuring pro-poor growth}

We assume that a measure of pro-poor growth should satisfy the following conditions:

Axiom 1. The measure should be consistent with the way the level of aggregate poverty is measured in that a reduction (increase) in poverty must register a positive (negative) rate of pro-poor growth. ${ }^{6}$

Axiom 2. The measure of poverty implicit in the measure of pro-poor growth should satisfy the standard axioms for poverty measurement, following Sen (1976). We take three such axioms to be essential, namely the focus axiom (the measure is invariant to income changes for the non-poor), the monotonicity axiom (any income gain to the poor reduces poverty), and the

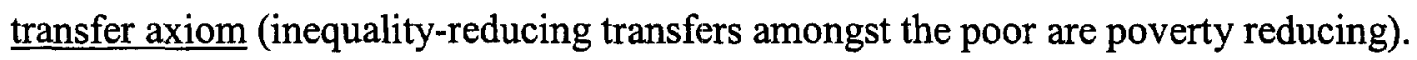

The headcount index clearly fails the monotonicity and transfer axioms. Amongst the numerous measures satisfying all three axioms, we focus on the Watts (1968) index:

$$
W_{t}=\int_{0}^{H_{t}} \log \left[z / y_{t}(p)\right] d p
$$

\footnotetext{
$4 \quad$ This follows, under mild assumptions, from well-known results on tax progressivity and inequality; see for example Eichhorn et al., (1984).

5 An exception is when the overall mean rises and the GIC is decreasing in $p$; then there is clearly second-order dominance. More generally, second-order dominance is tested by integrating over either the quantile function (Shorrocks, 1983), or its inverse, the CDF.

6 In the context of the inter-temporal aggregation of growth rates, Kakwani (1997) argues that the growth rate should be consistent with an aggregate welfare function defined on mean incomes over time.
} 
where $H_{t}=F_{t}(z)$ is the headcount index of poverty and $z$ is the poverty line. (Zheng, 1993, gives an axiomatic derivation of the Watts index.) To find a measure of growth consistent with the Watts index, differentiate (3) with respect to time and note that $y_{t}\left(H_{t}\right)=z$ :

$$
\frac{d W_{t}}{d t}=-\int_{0}^{H_{t}} \frac{d \log y_{t}(p)}{d t} d p
$$

This is approximately minus one times the integral of the GIC up to the headcount index.

Equation (4) motivates measuring the pro-poor growth rate $(P P G)$ by the mean growth rate for the poor:

$$
P P G_{t} \equiv \frac{1}{H_{t-1}} \int_{0}^{H_{t-1}} g_{t}(p) d p
$$

We define the poor as those living below the poverty line at the initial date $t-1$, in keeping with the common practice of measuring performance relative to the base date. (This does not matter in (4), given that the calculus is based on infinitely small changes.)

Notice that the measure in (5) is not the same as the growth rate in the mean income of the poor (as often used in applied work). The latter measure does not satisfy either the monotonicity or transfer axioms. If an initially poor person above the mean escapes poverty then the growth rate in the mean for the poor will be negative; yet poverty has fallen. This problem is avoided if one fixes $H$ over time, but then the measure fails the focus and transfer axioms.

\section{An illustration for China in the 1990s}

Figure 1 gives our estimate of China's GIC for 1990-99. We have calculated this from detailed grouped distributions for rural and urban areas separately; the distributions were 
constructed to our specification by China's National Bureau of Statistics. ${ }^{7}$ Urban and Rural Consumer Price Indices have been applied to the urban and rural distributions prior to aggregation, assuming a $10 \%$ differential in the cost-of-living between urban and rural areas at the base date. (Sensitivity was tested to a $20 \%$ differential and zero differential, but these changes shifted the GIC only slightly.) We then used parameterized Lorenz curves to calculate mean income at each quantile; we tested both the general elliptical and the incomplete beta specifications (Datt and Ravallion, 1992), and found that the former gave a better fit.

There is first order dominance. Thus poverty has fallen no matter where one draws the poverty line or what poverty measure one uses within a broad class (Atkinson, 1987; Foster and Shorrocks, 1988). The curve is also strictly increasing over all quantiles, implying that inequality rose. The annualized percentage increase in income per capita is estimated to have been about $3 \%$ for the poorest percentile, rising to $11 \%$ for the richest.

Table 1 gives our measure of the rate of pro-poor growth (equation 5, using numerical integration) for a range of poverty lines; for example, the rate of pro-poor growth is $3.9 \%$ for $H=0.15$. The mean growth rate over the entire distribution is $5.9 \%$. The growth rate in the mean is $6.9 \%$ per annum.

We repeated these calculations for sub-periods, 1990-93, 1993-96, 1996-99. All GIC's showed the same pattern except 1993-96, which is given in Figure 2. The GIC changed dramatically in this period, taking on an inverted $U$ shape, with highest growth rates observed at

7 The distributions published distributions in the China Statistical Yearbook (for example, NBS, 2000) are less than ideal for our purpose since they do not give mean income by class intervals and are quite aggregated (more so in some years than others). 
around the $20^{\text {th }}$ percentile. ${ }^{8}$ The rate of pro-poor growth for this sub-period is $9.8 \%$ per annum $(H=0.15)$ - above the ordinary growth rate of $8.4 \%$.

\section{Conclusions}

For the purpose of monitoring the gains to the poor from economic growth, the growth rate in mean consumption or income of the poor has the drawback that it is inconsistent with one or more standard axioms for measuring the level of poverty. This paper has argued that a better measure of "pro-poor growth" is the mean growth rate of the poor, which is consistent with a theoretically defensible measure of the level of poverty, namely the Watts index. The proposed measure of pro-poor growth can be readily derived from a "growth incidence curve" giving rates of growth by quantiles of the distribution of income. This curve is also of interest in its own right, as a means of describing how the gains from growth were distributed.

China's growth process in the 1990 s has been used to illustrate the proposed measure of pro-poor growth. Over 1990-99, the ordinary growth rate of household income per capita was $7 \%$ per annum. The growth rate by quantile varied from $3 \%$ for the poorest percentile to $11 \%$ for the richest, while the rate of pro-poor growth was around $4 \%$. The pattern was reversed for a few years in the mid-1990s.

\footnotetext{
8 A likely reason is the substantial increase in the government's purchase price for foodgrain in 1994 (World Bank, 1997). Arguably, this was not a sustainable change in relative prices. But it does appear to have entailed a substantial temporary shift in distribution, given that farmers are known to be concentrated around the lower end of the distribution of income in China (Ravallion and Chen, 1999).
} 


\section{References}

Atkinson, A.B., 1987, “On the Measurement of Poverty," Econometrica 55: 749-764.

Chen, S., and M. Ravallion, 2001, "How Did the World's Poorest fare in the 1990s," Policy Research Working Paper, World Bank, Washington DC,

Datt, G., and M. Ravallion, 1992, "Growth and Redistribution Components of Changes in Poverty: A Decomposition with Application to Brazil and India" , Journal of Development Economics, 38: 275-295.

Dollar, David and Aart Kraay, 2000, "Growth is Good for the Poor", Policy Research Working Paper, World Bank.

Gastwirth, J.L., 1971, “A General Definition of the Lorenz Curve”, Econometrica 39: 1037-39.

Eichhorn, W., H. Funke, and W.F. Richter, 1984, “Tax Progression and Inequality of Income Distribution," Journal of Mathematical Economics 13: 127-131.

Foster, J., and A.F. Shorrocks, 1988, "Poverty Orderings," Econometrica 56: 173-177.

Kakwani, Nanak, 1997, "Growth Rates of Per-Capita Income and Aggregate Welfare: An International Comparison," Review of Economics and Statistics 79: 202-211.

Moyes, Patrick, 1999, "Stochastic Dominance and the Lorenz Curve," in Jacques Silber (ed), Handbook on Income Inequality Measurement, Boston: Kluwer Academic Publishers.

National Bureau of Statistics, 2000, China Statistical Yearbook, Beijing: China Statistics Press.

Pen, Jan, 1971, Income Distribution, New York: Praeger Publishers.

Ravallion, M., and S. Chen, 1999, "When Economic Reform is Faster than Statistical Reform: Measuring and Explaining Inequality in Rural China", Oxford Bulletin of Economics and Statistics, 61: 33-56. 
Sen, A.K., 1976, "Poverty: An Ordinal Approach to Measurement," Econometrica 44:219-231.

Shorrocks, A.F., 1983, "Ranking Income Distributions," Economica 50, 3-17.

Watts, H.W. (1968). “An Economic Definition of Poverty,” in D.P. Moynihan (ed.), On Understanding Poverty. New York, Basic Books.

World Bank, 1997, China 2020: Sharing Rising Income, World Bank, Washington DC.

Zheng, Buhong, 1993,. “An Axiomatic Characterization of the Watts Index,” Economics Letters. $42,81-86$ 
Figure 1: Growth incidence curve for China, 1990-1999

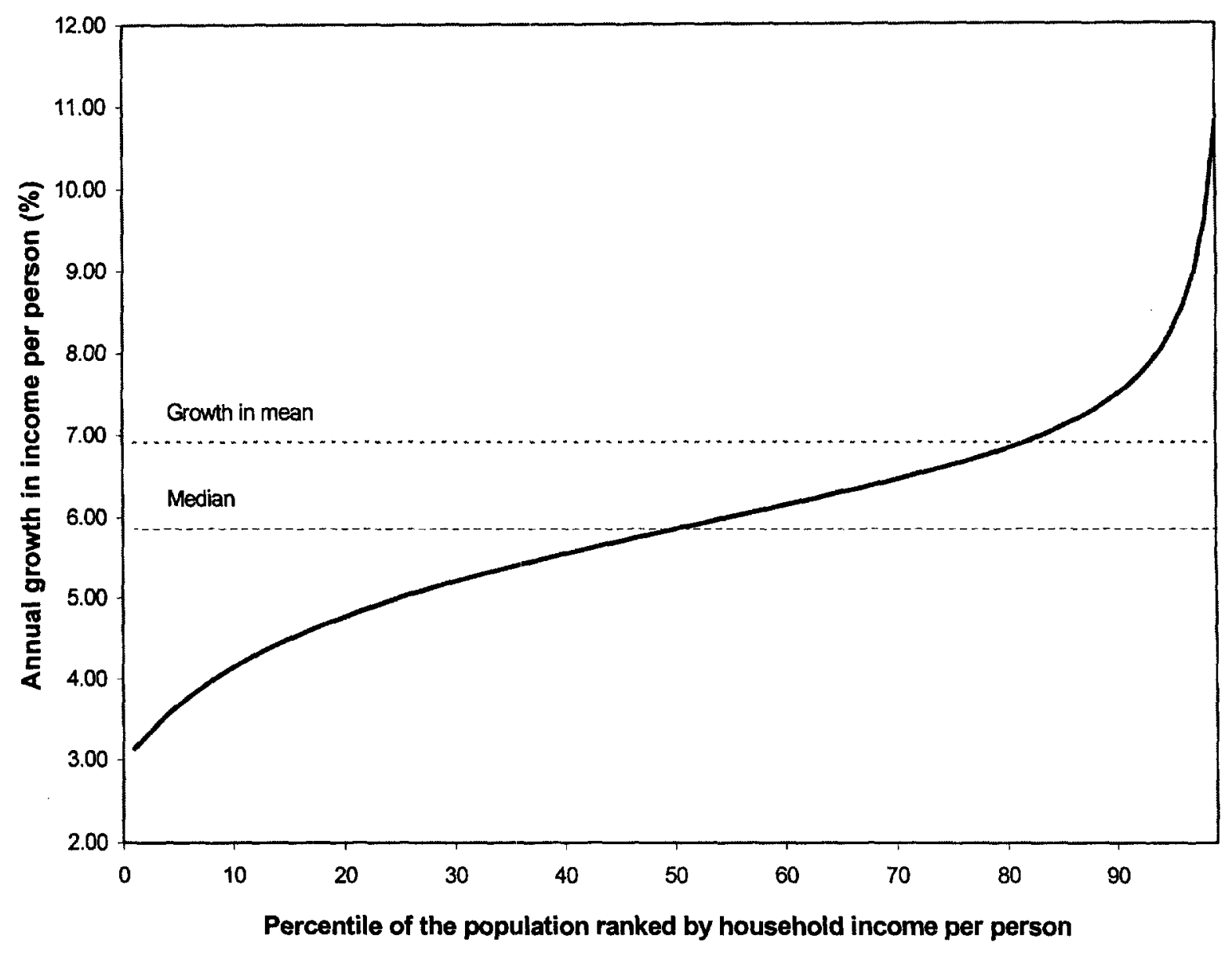

Table 1: Growth rates

\begin{tabular}{ccc}
\hline & $1990-99$ & $1993-96$ \\
\hline & \multicolumn{2}{c}{ Growth rate in the mean } \\
& \multicolumn{2}{c}{ (\% per annum) } \\
& 6.9 & 8.4 \\
\hline Headcount index (\%) & \multicolumn{2}{c}{ Rate of pro-poor growth } \\
\multicolumn{3}{c}{ (\% per annum): } \\
10 & 3.7 & 9.4 \\
15 & 3.9 & 9.8 \\
20 & 4.1 & 10.0 \\
25 & 4.3 & 10.1 \\
100 & 5.9 & 9.4 \\
\hline
\end{tabular}


Figure 2: Growth incidence curve for China, 1993-1996

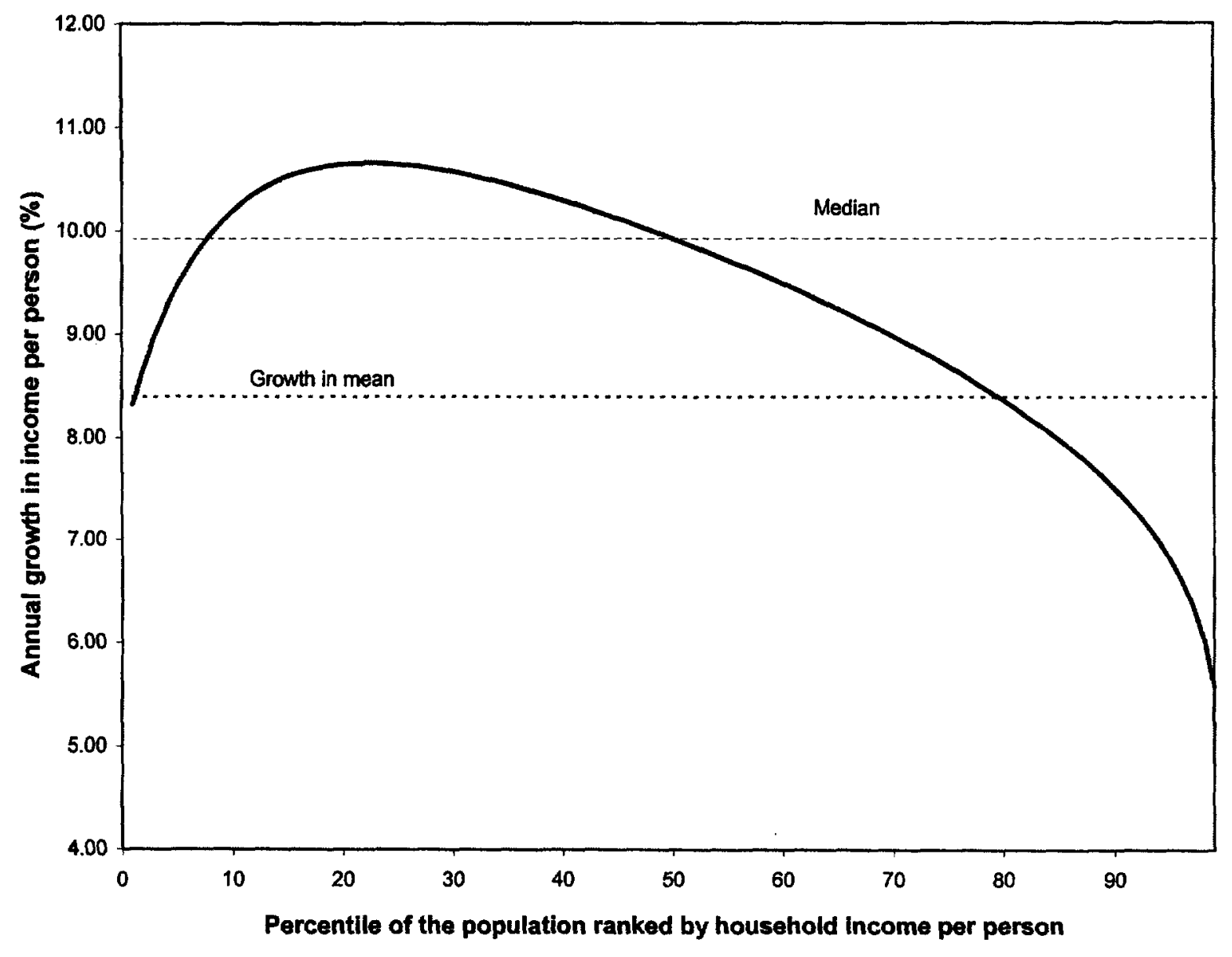




\section{Policy Research Working Paper Series}

Title

WPS2641 Is Russia Restructuring? New Evidence on Job Creation and Destruction
Author

Harry G. Broadman

Francesca Recanatini

Ilker Domaç

Kyles Peters

Yevgeny Yuzefovich

WPS2643 Dollarization and Semi-Dollarization in Paul Beckerman Ecuador

WPS2644 Local Institutions, Poverty, and Household Welfare in Bolivia

WPS2645 Inequality Convergence

WPS2646 Foreign Direct Investment and Integration into Global Production and Distribution Networks: The Case of Poland

WPS2647 The Politics of Monetary Sector Cooperation among the Economic Community of West African States

Deepa Narayan

Martin Ravallion

Bartlomiej Kaminski

Beata K. Smarzynska

Chibuike U. Uche 1952-99: Incorporating Human Capital Yudong Yao Accumulation

WPS2651 China's Growth and Poverty Reduction: Trends between 1990 and 1999

WPS2652 Demand for World Bank Lending

WPS2653 The Impact of Farm Credit in Pakistan

Shahidur R. Khandke Rashidur R. Faruqee

WPS2654 Thirst for Refor? Private Sector Participation in Providing Mexico City's Water Supply
Shaohua Chen Yan Wang

Dilip Ratha

Luke Haggarty

Penelope Brook Ana Maria Zuluaga
Date

July 2001

July 2001

July 2001

July 2001

July 2001

July 2001

July 2001

Contact

for paper

S. Craig

33160

A. Carcani 30241

P. Holt 37707

G. Ochieng 31123

P. Sader 33902

L. Tabada 36896

A. Al-Mashat 36414

M. Correia 39394

H. Sladovich 37698

A. Datoloum 36334

July 2001

A. Datoloum 36334

July 2001

S. Crow 30763

August 2001

P. Kokila 33716

August 2001

P. Sintim-Aboagye 37644 


\section{Policy Research Working Paper Series}

Title

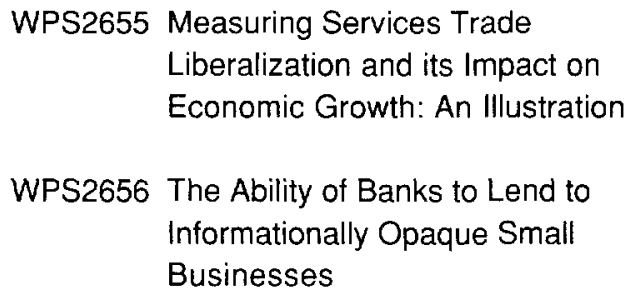

WPS2657 Middle-Income Countries: Development Challenges and Growing Global Role

WPS2658 How Comparable are Labor Demand Elasticities across Countries?

WPS2659 Firm Entry and Exit, Labor Demand, and Trade Reform: Evidence from Chile and Colombia

WPS2660 Short and Long-Run Integration: Do Capital Controls Matter?

WPS2661 The Regulation of Entry

WPS2662 Markups, Entry Regulation, and Trade: Does Country Size Matter?

WPS2663 Agglomeration Economies and Productivity in Indian Industry

WPS2664 Does Piped Water Reduce Diarrhea for Children in Rural India?

WPS2665 Measuring Aggregate Welfare in Developing Countries: How Well Do National Accounts and Surveys Agree?
Author

Date

August 2001

Randeep Rathindran

Arvind Subramanian

Allen N. Berger

Leora F. Klapper

Gregory F. Udell

Peter Fallon

Vivian Hon

Zia Qureshi

Dilip Ratha

Pablo Fajnzylber

William F. Maloney

Pablo Fajnzylber William F. Maloney

Eduardo Ribeiro

Graciela Kaminsky

Sergio Schmukler

August 2001

Simeon Djankov

Rafael La Porta

Florencio Lopez de Silanes

Andrei Shleifer

\section{Bernard Hoekman \\ Hiau Looi Kee \\ Marcelo Olarreaga}

Somik Lall

Zmarak Shalizi

Uwe Deichmann

Jyotsna Jalan

Martin Ravallion

Martin Ravallion

August 2001

August 2001

August 2001

August 2001
E. Khine 37471

L. Tabada

36896

R. Yazigi

37176

C. Cunanan 32301

Contact for paper

L. Tabada 36896

A. Yaptenco 31823

D. Fischer 38656

A. Pillay 88046

A. Pillay 88046

R. Vo 33722

C. Cunanan 32301 